\title{
An Internet of ownership: democratic design for the online economy
}

\author{
Nathan Schneider \\ University of Colorado Boulder \\ PREPRINT \\ The Sociological Review 66, no. 2 (2018) \\ $10.1177 / 0038026118758533$
}

The disappointments of the online economy - for instance, user surveillance and systemic labor abuses - stem at least in part from its failures to meaningfully share ownership and governance with relevant stakeholders. Under the banner of 'platform cooperativism', an emerging network of cooperative developers, entrepreneurs, labor organizers and scholars is developing an economic ecosystem that seeks to align the ownership and governance of enterprises with the people whose lives are most affected by them. This represents a radical critique of the existing online economy, but it's also a field of experimentation for alternative forms of ownership design. This essay presents and analyzes some of the ways platform cooperativism has begun to generate ownership designs that could serve the platform economy of the future differently than the investor-owned structures that currently prevail.

This essay stems from an ongoing collaboration with Trebor Scholz, and while he is innocent of my oversights, I am indebted to his insights. The following has also benefited from the input and feedback of Devin Balkind, Josef Davies-Coates, Enric Duran, Daniel Hu, Brent Hueth, Tim Kuhn and Keith Taylor, in part through an open review process at https://ioo.coop.

On March 18, 2016, at a press conference with US Secretary of Labor Thomas E. Perez on his right and a platform user named Ty Lane on his left, Managed by Q CEO Dan Teran announced, 'Over the next five years, Managed by Q 
will give 5 percent of the company to the operators working in the field. ${ }^{1}$ On the backdrop behind them, Managed by Q's logo - a futuristic, sans-serif grey $Q$ repeated over a black background, much like Uber's $U$ - evoked the company's status as one of the many trying to be 'the Uber for $x$ ' - in this case, the Uber for office-cleaning. But Teran's announcement represented a departure from Uber's notorious disavowal of employment responsibility for its drivers, whom it seems impatient to supplant with self-driving cars. In addition to full-time jobs and benefits, Managed by $\mathrm{Q}$ was welcoming the platform's worker-users as genuine co-owners.

Co-ownership has mostly been missing in the implicit social contracts of online platforms - the Internet-enabled, multi-sided markets that employ networked forms of connection and transaction to transform industries, workplaces and livelihoods (Parker et al., 2016). The principal owners of platforms, along with founders, have been the investors who inject capital in expectation of generous returns. Technology companies may offer stock options to early employees; users, in contrast, have been treated like external customers. Yet in many cases they don't pay the company any money while contributing essential content (e.g., virtually everything one encounters on platforms like Facebook or Reddit), even entrusting to the platform their personal data and their livelihoods. Platforms train users to think of themselves as participants in 'peer production' (Benkler, 2007) and a 'sharing economy' (Schor, 2014). But the online economy's ownership structures habitually fail to reflect either the platforms' stated aspirations or their social realities.

Managed by Q's directors, however, recognized that its office-cleaning 'operators' were a class of users that served as the company's face to the office-owning clients who provided revenue; co-ownership, therefore, seemed like an appropriate way to incentivize operators to take their responsibility seriously. The announcement also made for good press.

Canonical notions of corporate structure and governance, even when they encompass a wide variety of stakeholders, tend to affirm the practice of granting ownership and control to investors, since they bear direct financial risk (Jensen, 2000; Monks and Minow, 2008; Parmar et al., 2010). But when platforms hold near-monopoly status and wield control over urban transportation networks or data about intimate relationships, their risk profile is more complex than a share price. Platforms increasingly act as infrastructure, enabling productive activity among users - from individuals to large organizations. They're not just a means of production but a means

\footnotetext{
${ }^{1}$ https://vimeo.com/159580593.
} 
of connection. These webs of dependency, however, have not reached the platforms' boardrooms. Managed by Q's experience, together with a growing body of research on cooperative models, suggests that platform builders may be missing out on opportunities shared ownership could present - from retention, loyalty and diversity among their users to untapped potential for financing and public benefit (Albæk and Schultz, 1998; Davidson, 2016; Hueth, 2014; Molk, 2014; Pérotin, 2016).

The platforms now vying for dominance have tended not to maintain high labor standards among user-workers and other contractors, even bending the law in the process (Scholz, 2016b, Slee, 2016). Platform-based workers typically lack the expectation of coverage for illness, injury and retirement. The allure is real, as platforms offer the possibility of independent livelihoods, a departure from the drudgery and discipline of an old-fashioned job. But platform owners enjoy the far more lucrative benefits of having a fluid workforce without a large, fixed payroll. Investor-owners have little to lose and much to gain from sidestepping the conventional responsibilities of employment.

Less visibly, the mismatch between the interests of platform owners and users presents itself in the realm of data. Ubiquitous platforms like Facebook and Google, as well as others that operate more discreetly, gather reams of data about Internet users and offer it as a product. This data supplies a growing surveillance economy based on targeted advertising and pricing, which, intentionally or not, easily bleeds into discrimination of already marginalized populations (Bernasek and Mongan, 2015; Couldry, 2016; Pasquale, 2015). Although a platform like Facebook may insist that users retain ownership of their data, immense and illegible service agreements grant the platform such sweeping rights over that data as to render user ownership close to meaningless. Additionally, the prospect that one's online activity might affect a credit rating, or find its way into the database of a spy agency, has already dampened the free speech that the Internet once promised.

As the platform economy reorients how industries operate, it should also challenge taken-for-granted corporate ownership models. Cooperative ownership not only shares wealth more equitably among participants, but it also unlocks efficiencies by reducing the costs of transacting and contracting with an enterprise's essential stakeholders (Bogetoft, 2005; Hansmann, 2000; Hueth, 2014; Molk, 2014; Taylor, 2015). Online platforms have yet to enjoy the value and benefits of this model. The time seems especially ripe to take up the challenge that Marjorie Kelly (2012) has described as 'ownership 
design': What ownership structures are appropriate, competitive and just for an economy orchestrated through platforms? How can corporate structure better align the feedback loops of actual online sociality?

One collective effort to address these questions, and one in which I have been involved, has come to be called 'platform cooperativism'. As well as a rhetorical insurgency, this initative has opened a space of experimentation in online ownership design, taking inspiration from the legacy and ownership designs of the mostly offline cooperative movement. I will present and analyze here some of the ways platform cooperativism has begun to generate ownership designs that may serve the platform economy of the future differently than have the investor-owned structures that currently prevail.

\section{'The next sharing economy'}

Cooperative economies of some kind have probably existed as long as human economies in general. But in parallel with the rise of industrial capitalism, they have formed a distinct and transnational sector, with shared values and business practices of its own. From local food and housing co-ops to vast co-ops of farmers, retail stores, or electric utilities, this sector generates over $\$ 2.2$ trillion in turnover worldwide, often in ways that serve needs unmet by investor-owned businesses. ${ }^{2}$ It's a part of the global economy widely relied upon yet overlooked, a 'sharing economy' before Silicon Valley adopted the term.

The prospect of platform cooperativism is at once new and old among the cultures surrounding the Internet. Early software and hardware hackers employed certain cooperative-like practices as they assembled the rudiments of the personal computer and the means of networking them. They shared source code; they developed structures of democratic governance across great distances; they resisted corporate enclosure in the process (Benkler, 2007; Coleman, 2012; Kelty, 2008). Small groups of software developers have formed successful worker-cooperatives. ${ }^{3}$ Some of tech culture's innovations deserve to be studied more closely by the offline cooperative movement, as they demonstrate the plausibility of, and some proven techniques for, highly distributed and productive self-management; many co-ops emerging among young people today are organized around tech culture's flexible,

\footnotetext{
${ }^{2}$ http://ica.coop/en/facts-and-figures.

${ }^{3}$ A directory of North American examples is available at https://techworker.coop and, for the United Kingdom, https://coops.tech.
} 
networked forms of connection rather than recreating industrial-era jobs and membership societies. Platform cooperativism, therefore, is not starting from scratch in tech culture.

Still, true cooperative business models have been almost entirely absent from the online economy. One can at least speculate about the reasons why. The disruptive efficacy of the venture-capital financing mechanism has rendered it a go-to blueprint to the exclusion of other approaches. The technological sophistication necessary to build online enterprises has also proved prohibitive for the often-marginalized communities that tend to adopt cooperative strategies. And until recently the Internet could be considered an optional realm of activity; co-ops tend to appear when people have an unmet need, not to furnish a mere accessory or curiosity. But it is becoming harder and harder, around the world, to secure a livelihood without taking part in the online economy. Perhaps this is why, in the past few years, recognizable platform co-ops have begun to appear.

The Spanish collective Las Indias distinguished platforms as one type of cooperative in a 2011 blog post (de Ugarte). In 2012 the Italian federation Legacoop promulgated a manifesto for 'Cooperative Commons', stressing the need for cooperative business models to manage the growing stores of data that users feed to online platforms. ${ }^{4}$ Stocksy United, a stock-photo platform owned by its photographers, went online the following year. By 2014, Janelle Orsi, founder of the Sustainable Economies Law Center in Oakland, was calling for "the next sharing economy" ${ }^{5}$ - the sharing of cooperative ownership - and was helping to design the bylaws for Loconomics, a gig platform owned by its workers. Sharing-economy venture capitalist Lisa Gansky was calling for sharing ownership through co-ops, too (Said, 2014; Gansky, 2014). ${ }^{6}$ I began documenting such projects in collaboration with the online newsletter Shareable (Schneider, 2014); meanwhile, drawing on the lessons of his Digital Labor conferences at The New School, Trebor Scholz coined the term 'platform cooperativism' as an alternative to the systemic abuses of investor-owned platforms (Scholz, 2014 and 2016a). In consultation with labor organizations and platform workers, Scholz and I co-organized the 2015 Digital Labor conference, 'Platform Cooperativism: The Internet, Ownership, Democracy', and co-edited a subsequent book, Ours to Hack and to Own (2017). People around the world trying to develop

\footnotetext{
${ }^{4}$ http://cooperativecommons.coop/index.php/en/manifesto.

${ }^{5}$ https://youtube.com/watch?v=xpg4PjGtbu0.

${ }^{6}$ This sentence is a post-publication addition and correction; thanks to Martijn Arets for the reminder.
} 
online platforms through democratic ownership and governance began to coalesce their scattered efforts into a new economic ecosystem.

Since early 2015, along with Devin Balkind of Sarapis and others, I have maintained The Internet of Ownership ${ }^{7}$, the most exhaustive directory to date of the platform co-op ecosystem, and I lean heavily on that experience here. The directory includes not only 'co-op platforms' (which adhere to the International Co-operative Alliance's standards for cooperative identity, detailed below) and various tools and organizations that support them, but also 'sharing platforms' (like Managed by Q) that practice shared ownership or governance with platform users, at least in part.

Platform cooperativism can likewise be taken to mean a broad invitation to a fairer online economy through shared ownership and governance; platform co-ops, however, are strictly those platforms that are also bona-fide co-ops by widely agreed-on standards (Sutton et al., 2016). The most recent revision of the principles that the International Co-operative Alliance holds, ${ }^{8}$ adopted in 1995, is as follows:

1. Voluntary and Open Membership

2. Democratic Member Control

3. Member Economic Participation

4. Autonomy and Independence

5. Education, Training and Information

6. Co-operation among Co-operatives

7. Concern for Community

To clarify these, the ICA promulgates the accompanying 'values' of self-help, self-responsibility, democracy, equality, equity and solidarity.

Most of the cooperative principles resonate somewhat with the social contracts of the platform economy. 'Voluntary and open membership' is a default practice among platforms, which typically enable anyone (with access to requisite technology) to create an account; 'autonomy and independence', too, is a value that platform owners often assert while disrupting incumbent industries, even while proclaiming a well-meaning 'concern for community'. There is much 'co-operation' among platform companies as well, such as through API protocols and standards-setting organizations like the World Wide Web Consortium. Practices of 'education, training and information' often happen on platforms through much the kind of mutual education - in

\footnotetext{
${ }^{7}$ https://io.coop.

${ }^{8} \mathrm{http}: / /$ ica.coop/en/whats-co-op/co-operative-identity-values-principles.
} 
online forums and in-person meetups - that cooperatives encourage among their members.

The resonance, however, only goes so far. Principles two and three above democratic governance and ownership, crucially - are almost wholly absent from the platform economy. Online user-experience design often seeks to divert users' attention from matters of governance and ownership, such as by rendering opaque the processes of revenue generation through apparently 'free' services. Consultation with users on changes to features or policies is, at best, superficial.

Democracy itself has taken on a new meaning online. A Web search for 'democratize internet' or the like reveals that in tech culture 'democracy' has come to signify merely an expansion of access to various tools and resources, rather than the collective governance and joint stakeholdership to which the word, in other contexts, refers. That old kind of democracy is illegible to the Internet's dominant ownership designs. The contention of platform cooperativism is that the design of platform businesses, and thus of the online economy generally, can and should allow for democracy in the fullest sense. There is no one-size-fits-all solution, and cooperation won't necessarily produce the appropriate response to every design challenge. But these kinds of designs are worth at least considering far more than they have been in the online economy thus far.

I hope I can be forgiven for leaving the necessary, important task of raising objections about the value and prospects of platform cooperativism to others. I look forward to learning from them. But it has seemed to me a better use of this space to offer a broad sketch of the movement's progress. I hope, also, that the critiques of this nascent movement might come in the form of challenges rather than repudiations that could cut it at the root. It should be a foregone conclusion, but is too often not, that in a society that claims to be democratic, the advancement of democracy into new spheres of social life should be a question of how, not whether.

\section{Ownership designs}

In the following I introduce some of the design patterns (Alexander et al., 1977) that have so far arisen in the experimentation of platform cooperativism and related undertakings. Most of the projects referred to can be found in The Internet of Ownership directory, as well as the 'showcases' in Ours to 
Hack and to Own. I draw from published material on their websites and my conversations with their participants. While nearly all are too early-stage for a thoroughgoing evaluation, the patterns they embody at least trace the outlines of a new palette of options for ownership design in the online economy.

\section{Work: Value creators as value owners}

Amazon's Mechanical Turk platform, which enables posting and carrying out piece-work tasks (tag some images, transcribe a recording, fill out a survey), gets its name from an eighteenth-century curiosity in which a human chess player sat discreetly inside a machine, dazzling the public and contemporary notables alike with its apparently mechanical intelligence. The reference is too apt for comfort; the human beings working on Mechanical Turk appear through the platform almost as if they were just another algorithm. Starting in 2014, these workers mounted a widely publicized email-writing campaign called 'Dear Jeff Bezos', alerting the Amazon CEO to the fact that 'Turkers are not only actual human beings, but people who deserve respect, fair treatment and open communication. ${ }^{9}$

Workers on Mechanical Turk, for instance, enjoy no minimum wage or ability to rate the behavior of the pseudonymous employers who meanwhile rate theirs. And while this case is egregious, it is not unique. In 2016, as many as 24 percent of US adults reported earning income on platforms (Smith, 2016). The prevailing platform business model is to achieve scale while reducing labor costs and interference in management, automating tasks wherever possible.

Platform cooperativism inclines toward another approach, one in which the people contributing value co-own the platforms and help decide to what ends they operate. The aforementioned Loconomics, for instance, is a platform co-op for short-term gigs in which the workers are co-owners; unlike 'Turkers', who rarely receive replies from Amazon when they submit complaints, Loconomics is designed to benefit from worker participation in governance. Its worker-owners invest in the platform through periodic dues. Also in the San Francisco area, the SEIU United Healthcare Workers West union is backing the Nursing and Caregivers Cooperative, through which the nurses collectivize and co-mange the terms under which they deploy

\footnotetext{
${ }^{9}$ http://wearedynamo.org/dearjeffbezos.
} 
their labor on their app, NursesCan. The stock-photo platform Stocksy United, incorporated as a Canadian cooperative, has found that including the photographers as members (alongside staff and founders) is a way of recruiting more talented contributors than might otherwise be possible, and of prioritizing artistic quality over ruthless expansion.

Part of securing fair work-lives on platforms is the development of 'portable benefits' that don't rely on any one employer, but that better suit the promiscuous connectivity of a platform economy. This, too, is a job well suited to co-op models - hearkening back to the cooperative mutuals that gave birth to the modern insurance industry. The Freelancers Union in the United States and SMart in Europe are membership organizations that have delivered benefits to many thousands of independent workers, relying heavily on online tools. This kind of model, often in cooperative forms, is proliferating rapidly (Conaty et al., 2016).

The storied successes of twentieth-century worker cooperativism - such as the Mondragon Corporation in the Basque Country and the Emilia-Romagna region of Italy - sought to secure full-time industrial jobs. But many in the latest generation of co-ops seem designed to free their members from the need for a job altogether. Prime Produce, for instance, is a cooperative coworking space in New York City that prefers the language and ethic of 'craft' over 'work'; the New Zealand-based cooperative network Enspiral aspires to redefine work as 'stuff that matters'. 'Open companies' (such as Gratipay, a crowdfunding platform) or 'open value networks' (such as Sensorica, which develops scientific instruments) have sought to rely on no employees at all, but to create products by rewarding the contributions of participants through a distributed platform. In Barcelona and the surrounding region, the Catalan Integral Cooperative draws member-owners in first by facilitating freelance work, and then by enabling them to obtain food, housing and services through internal trade and mutual credit rather than relying on euros. Some of its members have been involved in creating FairCoop, which proposes to do much the same on a global scale by connecting local 'nodes' through online tools, including a cryptocurrency called FairCoin (Schneider, 2015b).

Platforms need not regard those who contribute value through them as temporary stand-ins for algorithms. By orienting their business models around such contributors, platforms can provide not only decent livelihoods, but also a means of bypassing dependency on employment relations altogether. 


\section{Data: Treat it like it's someone's stuff}

Much as Mechanical Turk disguises value-contributing workers behind a platform, business models based on so-called 'big data' often seek to disguise the fact that they're capturing value from those contributing it. Facebook, for instance, provides extensive privacy controls by which users can customize what other users see about them - few of which affect, however, what Facebook itself sees, records and claims license to monetize. The economic power and promise of large pools of human data depend on the relinquishment of certain ownership rights by the humans involved, such as through opaque service agreements. These pools, in turn, can become outsourced repositories for government intelligence and law-enforcement agencies.

What would less duplicitous ownership designs for data look like? Commodify.us, for instance, has pioneered a model by which users can download a copy of their data from Facebook, then re-upload it, selecting which license they would like to apply to each data set - allowing them to monetize their data on their own terms. A more developed version of that general idea is TheGoodData, a London-based co-op, which allows users to monetize their browsing data with a browser extension and donate the proceeds to charitable causes. Meanwhile, under the aegis of MIT and the Qatar Computing Research Institute, an ambitious initiative called Solid ('SOcial Linked Data') proposes a framework for a new species of social applications based on modular, consensual data-sharing agreements, granting users granular control over what they share.

Given the centrality of trust and ownership in matters of data, particularly highly personal data, cooperative business models may be especially well suited to building data economies that are both transparent and competitive. Starting with highly sensitive medical data, the Swiss platform MIDATA.coop is developing a business model for personal data storage based on cooperative ownership and governance, together with secure open-source software. In the United Kingdom, a research project called OurData.coop is exploring the potential for a widespread system of such data co-ops, through which people could both retain control over and selectively monetize data that they produce.

A further use-case for data co-ops is in practicing the sixth cooperative principle of cooperation among cooperatives. Already, established co-ops like Ringlink Scotland (which supports agricultural business development) facilitate data-sharing among their members. Newer projects, such as the 
U.S.-based Data Commons Cooperative and CoopData.org, seek to provide platforms for data-sharing among co-ops that can help them find each other and work together. The promise of big data need not depend on ambiguous or misleading ownership arrangements.

\section{Code: Keep the lords' hands out of the commons}

At least since the Charter of the Forest that accompanied the Magna Carta, people who live by and co-manage common resources have found the need to protect them from the acquisitive tendencies of those at the top of the social pyramid (Linebaugh, 2009). In order to protect the code-sharing habits of early hacker culture from the proprietary urges of corporations and universities, Richard Stallman inaugurated the Free Software movement with the GNU Public License in 1989. This and similar 'copyleft' licenses were quintessential hacks, turning intellectual-property law against itself by employing an author's copyright privileges in order to liberate her code into a commons, free for anyone - with the requisite skills, equipment and time - to use, adapt and improve. Legal scholar Lawrence Lessig pioneered the transfer of this same hack to non-software cultural production through the array of Creative Commons licenses (Bollier, 2008). The accomplishments of this movement have been remarkable; copyleft practices have insinuated themselves into the modus operandi of the mainstream tech industry, creating many billions of dollars worth of freely available, world-class software in the process.

The tradition of hacking intellectual-property law, however, has not extended to the challenge of hacking corporate structure and corporate profits; as a result, there has been a disconnect between production, governance and ownership. The terminology of 'open source', which emerged about a decade after Stallman's GPL, advertised collaborative code-sharing as an opportunity for low-cost, crowdsourced corporate innovation. Many of the large opensource projects now operate through foundations guided and funded by corporations that benefit from the community-developed code. Google, for instance, has been able to redeploy the open-source Linux kernel as Android, the world's most popular mobile operating system, which also happens to be an effective tool for transmitting lucrative user data to the company's proprietary databases.

The leading online peer-production communities, like Wikipedia and Linux, have also remained troublingly homogeneous, with low rates of participation 
among women and (at least in the United States) non-white ethnicities. Explanations for this in such communities range from instructive to denialist. But the reality is that those engaged in peer production must either be paid to do so or have surplus leisure time - a surplus that less-privileged populations are less likely to have (Dryden, 2013). By relinquishing ownership of intellectual property to this kind of commons, peer producers may have actually amplified some of the inequalities of the society around them, while allowing corporations to reap the profits. Corporate-led open-source development, too, has cultivated highly sophisticated back-end tools while leaving the features that are user-facing - that is, customer-facing - far less well developed, rendering them unable to compete with commercial counterparts.

Many of platform cooperativism's early advocates have been advocates, too, of Free Software and the open-source movement. Stallman, as well as Free Software partisan Micky Metts, spoke at the 2015 New School conference. Some insist that platform cooperativism should include a commitment to the exclusive use and production of the GPL and similar licenses. Others in the community have embraced a new generation of intellectual-property hacks specifically attuned to corporate ownership design as well as the intellectual property itself.

Dmytri Kleiner's Telekommunist Manifesto (2010) outlined a proposal for a 'Peer Production License', which adapted the Creative Commons AttributionNonCommercial-ShareAlike license by adding a clause that permits commercial use by worker-owned enterprises that distribute surpluses solely to the worker-owners. If Linux were licensed in this way, Google couldn't make use of it but a worker-owned company developing mobile devices could. Lost is the mainstreaming effect of corporate adoption, but the value conjured by peer-producers is not so easily captured by capital. Co-ops gain a competitive advantage. The Peer Production License has been promoted by P2P Foundation founder Michel Bauwens (in Scholz and Schneider, 2016), and the platform co-op Guerrilla Translation has adopted it as a general policy though it remains marginal and largely untested in practice.

A more restrictive experiment in license innovation is the 'Co-op Source License' of the Co-op Source Foundation, a software-development platform coop. ${ }^{10}$ This license assigns profits from commercialized software to contributors based on "commitment level and peer review." CoMakery, while not itself a cooperative, is a startup developing a tool for distributing profits in this

\footnotetext{
${ }^{10}$ https://coopsource.org/\#license.
} 
kind of arrangement with the aid of blockchain technology.

Even without adopting additional restrictions, platform co-ops have sought to develop new strategies for connecting the immense value in the open-software commons with end-users. Snowdrift.coop, for instance, is a cooperative platform designed to provide sustainable financial support for projects that contribute to such commons; platforms like this could incentivize open-source developers to focus more attention on user interfaces that can compete with closed-source alternatives.

Platform cooperativists seek to add a more fair and explicit economic layer to peer-production, prevent corporate value capture and facilitate cooperation among cooperatives. Some of the more restrictive proposals could come at the cost of losing the broad user and contributor base that corporate adoption can offer. Yet each of these experiments represents a plausible innovation in its own right as well as a constructive critique of the Free Software and open-source legacies.

\section{Protocols: No decentralization without representation}

Defenders of a free and open Internet also cherish the network's decentralized design. While working at the RAND Corporation in the 1960s, Paul Baran developed the concept of distributed packet-switching as the basis of a communication system that wouldn't rely on any single node that could be vulnerable to Soviet attack (Baran, 2002). Despite notable exceptions such as the Domain Name System, this distributed logic pervades the Internet's protocols. The liberating promise of decentralized networks, in turn, seems to have inclined Internet denizens to seek further liberation through further decentralization. Technologies like peer-to-peer file sharing have allowed users - by relying on no central server - to share copyrighted music and video files without interference from the copyright holders. Platform cooperativism is in a sense a call for decentralization as well, in particular the decentralization of ownership.

The Internet as many people experience it has become remarkably centralized. They gain access through the monopolistic broadband providers that have replaced the small-scale, local ISPs that were common in the days of dial-up (although some regions co-own their broadband through cooperative utilities). Much of their online lives takes place through a small number of monolithic companies such as Facebook and Google - which track browsing 
habits through cookies, embedded buttons and mobile surveillance. But decentralization is also undergoing a revival, as early Internet architects like Tim Berners-Lee and Brewster Kahle call for re-decentralizing the Web. ${ }^{11}$ These initiatives seek to challenge the centralized platforms with a new generation of decentralized protocols. The cryptographic blockchain technology that enabled the Bitcoin digital currency system, meanwhile, makes possible a bewildering array of decentralized possibilities, from a replacement for the Domain Name System (e.g., Namecoin) to 'distributed autonomous organizations' made of 'smart contracts' (e.g., Ethereum). Advocates revel in the ambition of a 'trustless' 'decentralized society' that cryptography will allegedly enable (Frank, 2015). And in many respects the promise is real.

Bitcoin, however, has become a cautionary tale. While the underlying cryptography has held up according to spec, the social outcomes are less encouraging. Wealth distribution in the Bitcoin economy is massively stratified - much more so than in the conventional economy - and a small cabal of 'mining' pools have come to dominate the creation of new coins and the governance of the system. In effect, Bitcoin has become centralized yet ungovernable.

The urge to decentralize and distribute authority across networks risks neglecting the necessary work of reconstituting that authority in democratic ways. But decentralization and democracy can go hand in hand, too. For some years now, federated social networks like Diaspora, Friendica and GNU Social have implemented features familiar to users of Facebook and Twitter through decentralized networks of independently owned and governed nodes. I am a member of the 'democratic membership organization' May First/People Link, which finances, owns and manages a GNU Social node; my data for the network is managed, therefore, by an organization accountable to me, while enabling me to interact freely with the global network. This model, while less lucrative for investors than a centralized social network, is well suited to democratic organizations. Scale occurs through the protocol, not the platform.

The democratic potential of blockchain technologies, also, is considerable even if it has rarely prevailed in practice. While Ethereum smart contracts could implement a digital autocracy governed by an absolute monarch or an unaccountable robot, they're just as capable of facilitating highly democratic structures. Some projects have turned to cooperative models to solve problems that vex other blockchain systems; Rchain uses a co-op as

\footnotetext{
${ }^{11}$ E.g., their June 2016 conference: https://decentralizedweb.net.
} 
a means of scalability, while Moeda turns to credit unions as partners for expanding financial inclusion.

To those who regard decentralization as a liberatory end in itself, platform cooperativism adds the qualification that having a decentralized system doesn't remove the challenge of governance - it just alters where and how governance takes place. For decentralization to have democratic consequences, it needs democratic design.

\section{Finance: Rent capital, don't be rented by it}

Some assume that cooperatives are incompatible with large-scale financing, that they must forego the growth and innovation that investor ownership enables. A glance at the global cooperative sector, however, belies this. It is true that cooperatives cannot cede the powers of governance and ownership that investors typically expect, but in areas where co-ops have flourished, they have formed quite formidable financial institutions - such as credit unions and cooperative banks - to hold capital and make it available to the sector for growth. José María Arizmendiarrieta, founder of the Mondragon Corporation, insisted that co-ops have a responsibility to capitalize: 'A cooperativism without the structural ability to attract and assimilate capital at the level of the demands of industrial productivity is a transitory solution, an obsolete formula' (2013).

Rather than ruling out the possibility of financing, cooperative models require a different kind of ownership design in their financing schemes than businesses that invite investor control. Thus far, however, the online economy has relied on a venture-capital investment model based on granting considerable rights to early investors, followed by an eventual 'exit' through either selling the company to another company or trading shares on speculative markets. For platform cooperativism to take hold as a live option for enterprises, other designs are needed.

Loomio is a New Zealand-based worker co-op that produces a popular online decision-making platform. Venture capital was not an option, and the team members considered adopting non-profit status, but found it incompatible with their ambitions for scale. By early 2016, however, they had raised a round of $\$ 450,000$ from investors who supported their mission and regarded their worker-owned structure as adequate assurance. The investors purchased non-voting, redeemable-preference shares, assuring a return based on the 
company's revenue without compromising its cooperative model. While the investment remains a modest one by Silicon Valley standards, it beckons toward more sizable promise.

Cooperatives were, in a sense, the original crowdfunding, allowing communities to self-fund enterprises that served them. And while online crowdfunding has been an effective enabler of new initiatives, it lacks the shared ownership of co-ops. New platforms want to bring that back. Seedbloom is building an blockchain-based equity crowdfunding tool, enabling contributors to become co-owners of the projects they support; it has already helped enable the development of Resonate, a cooperative music-streaming platform owned by fans, musicians, and labels. Open Collective, while not a cooperative, is a crowdfunding tool that enables groups to form online cooperatives and manage their budgets without need for formal incorporation or a bank account. Tools like these can help significantly lower the barriers to co-op formation.

A vibrant platform co-op sector will require a variety of financing mechanisms. Purpose Ventures is an emerging investment firm designed from the start to specialize in 'self-owned', 'purpose driven' companies that seek sustainable growth, not a rapid exit; as the companies grow, their success enables new companies to join a mutually supporting ecosystem. FairCoop is attempting to create a global cooperative financial system with several concurrent mechanisms, including its own cryptocurrency, a mutual-credit network, a savings service and a variety of mission-driven funds.

A further source for platform co-op investment is the existing offline cooperative sector. While some large, well-capitalized co-ops have begun investing in platforms, they often face a learning curve in doing so. Just as the tech sector has yet to learn what it takes to systematically develop co-ops, the cooperative sector must learn how to apply its financial resources and knowhow online. One promising approach may be to forge collaborations between successful tech accelerators and cooperative financial institutions.

What unites these various forms of cooperative-friendly financing is how they reverse the conventional corporate model, in which capital rents workers' time and seeks to extract profit from customers. In co-ops, online and off, participants find capital when they need it and rent it without relinquishing their business in exchange. 


\section{Education: Train owners, not just workers}

The promotion of education has been a pillar of cooperative enterprise at least since the Rochdale Society of Equitable Pioneers' famous store in mid-nineteenth-century England, and it remains a basic principle for the global cooperative movement. Business shapes the people who engage in it as an implicit education; cooperativism seeks to make that education explicit, and to educate members as informed, empowered stewards and owners. Some of the world's most important co-op networks, including the Mondragon Corporation and the Antigonish movement in Nova Scotia, grew out of schools. It is an irony of Silicon Valley's history that Leland Stanford, founder of the tech industry's flagship university, was a passionate advocate of cooperative enterprise and included in his Grant of Endowment a directive 'to have taught in the University the right and advantages of association and co-operation'; it's an intention that the university, and the tech industry it helped spawn, has largely ignored (Altenberg, 1990).

In Scholz and Schneider (2016), a chapter by Karen Gregory asks in its title, 'Can Tech Schools Go Cooperative?' By 'tech schools', she refers to the recent proliferation of unaccredited, often for-profit 'bootcamps' that offer intensive curricula designed to produce students ready for well-paying jobs for software companies in a matter of only weeks or months. Gregory proposes, instead, a kind of tech school that sets the bar higher, to ownership: 'a curriculum that explores the possibilities of new forms of collectivities, organizing and worker agency'. Gregory calls for locating such schools in public universities, for the sake of accessibility for populations currently underrepresented in tech jobs. New programs in cooperative business at public institutions - such as the City University of New York and Laney College, a community college in Oakland, California - are currently in development, but by and large their orientation is toward offline cooperatives.

A model partly along the lines Gregory describes, meanwhile, has emerged through the New Zealand-based cooperative network Enspiral, which is home, among other enterprises, to Loomio. In 2014 members of the network formed Enspiral Dev Academy, a coding school that equips students with marketable skills while also introducing them to the opportunities for co-ownership in Enspiral itself. The academy offers scholarships and priority for applicants from underrepresented populations (as some more conventional tech schools do as well). Likewise outside the sphere of public education, the educational arms of cooperatives like Mondragon Corporation and Co-operatives UK 
offer distance-learning programs that could prefigure platform co-op models for massive open online courses (MOOCs) and the like.

Whether in public or private forms, education will be an essential component of a platform co-op sector. Some of the most important education likely takes place through the platforms themselves, in the ways by which a platform presents itself to members as a medium of co-ownership and elicits from them responsible decision-making and stewardship.

\section{Governance: Kumbaya won't do}

In co-ops and investor-owned companies alike, shared governance can turn into a caricature. Those with limited experience in the cooperative sector might assume that just because an enterprise is, say, legally owned by its workers, cumbersome consensus-based processes must be the norm. And in companies where the workers are not owners, managers might try similarly cumbersome performances to instill a fictional 'sense of ownership' intended to encourage more productive behaviors. Platform cooperativism has challenged both versions of superficial communalism by seeking to align appropriate ownership and governance structures rather than hiding one behind the other.

The task of efficiently balancing the stakeholdership relationships of the platform economy is far from straightforward. Traditional lines that distinguish worker-owned, consumer-owned, or producer-owned co-ops tend to blur in a platform economy where much of a platform's value comes from the contributions and resources of people who are not the company's employees. Many emerging platform co-ops have opted for multi-stakeholder models that encompass various classes of co-owners, such as employees, users and customers. The FairShares model, for instance, is a recent effort to facilitate and codify a multi-stakeholder structure. Platform co-ops like Loconomics, Resonate and Stocksy United use multi-stakeholder structures for both ownership and governance.

There are lessons to be drawn from the distributed governance models of foregoing tech culture. Open-source software communities have developed sophisticated governance practices, ranging from the formality of the Debian Constitution, which manages a popular version of Linux, to the free-for-all of an IRC channel. These hackers' commitment to transparency, also, can offer correctives to a cooperative movement that has too often been opaque, 
even to its members. Holacracy and sociocracy are governance structures that conventional companies have used to distribute authority and empower employees; they're even better suited to cooperative models in which that empowerment extends to ownership of the company itself.

Experiments that have emerged from civic and political innovation have proved useful for economic democracy, too. Loomio - which translated the decision making processes of Wellington, New Zealand's 2011 Occupy encampment into a platform - serves as a primary governance tool for Enspiral and other co-ops worldwide, along with schools, government programs and businesses. The 'liquid democracy' model pioneered among alternative political parties in Europe and South America could be well-suited for largescale platform co-ops.

There is potential for governance, also, in the now-reflexive daily practices of online platforms - Facebook 'likes', Reddit 'upvotes' and so forth. These features of user experience could become the rudiments of meaningful shared governance. If this were the case, we might see a reduction in the often careless behavior found on social media. Could the Reddit uprising of 2015, which ousted a CEO, have proceeded more constructively if Reddit users had levers for self-governance besides conspiring to shut down the platform?

Not every wheel of governance must be reinvented. For all the radical governance models on offer, platform co-ops need not necessarily reject every practice that conventional platform companies already employ - while retaining the significant difference that the managers are ultimately accountable not to outside investors but to the platforms' actual participants, as well as to the communities in which participants live.

\section{Policy: Local value for local benefit and control}

Confronting the platform economy's onrush of disruptions, policymakers have found themselves in the position of trying to say 'no', in various and sometimes futile ways, as they attempt to retain appropriate control over their economic infrastructures. Ride-sharing platforms destabilize structures for taxi regulation, and room-renting platforms unsettle tourism policies. Both bypass established compromises in labor relations. Industries that were once more or less locally governed and owned are now orchestrated from the platforms' headquarters far away - and those platforms' investors insist on taking a sizable cut. Platform cooperativism gestures toward a new set of 
options to consider, toward something policymakers can say 'yes' to.

Co-ops have long represented this kind of constructive alternative, and in many parts of the world their flourishing has been made possible through proactive policy. In the United States, for instance, the Department of Agriculture provided grants and loans for the creation of electric utility co-ops in rural areas that investor-owned companies opted not to electrify, starting in the 1930s; today, federal agencies have begun helping some of those same co-ops offer user-owned broadband service. Co-ops are a tool not only for meeting needs that capital markets fail to meet, but for doing so justly, in a way that keeps wealth among the constituencies that create it. To this effect, Michel Bauwens and others have theorized the 'partner state' as a framework for governments that enable, but do not control or direct, the flourishing of cooperative and commons-oriented enterprise (Kostakis and Bauwens, 2014). The city of Barcelona has taken early steps to enshrine platform cooperativism into its economic strategies. And in August 2016, UK Labour Party leader Jeremy Corbyn issued a 'Digital Democracy Manifesto' that included 'platform cooperatives' among its eight planks.

In her statement for the 2015 Platform Cooperativism conference, ${ }^{12}$ New York City Council member Maria del Carmen Arroyo wrote, 'Worker cooperatives offer a viable method to address the long-term challenge of reducing the number of chronically unemployed and underemployed residents and the number of workers trapped in low-paying jobs'. To this end, she had already supported legislation to fund worker-cooperative development in the city, as well as steps toward preferential treatment for co-ops in city infrastructure contracting. She added that platform cooperativism 'can put the public in greater control of the Internet, which can often feel like an abyss we are powerless over'. Another City Council member, Ben Kallos, made a lastminute appearance at the conference to announce his proposal for a 'Universal E-Hail App' with an open protocol that would level the competition between taxis and ride-sharing drivers.

Taking the example of the accommodations-rental platform Airbnb, Janelle Orsi has proposed three kinds of cooperative alternatives, outlining a distinct role for government in the ownership design of each (Schneider, 2015a). What she calls 'Co-bnb' would be a co-op owned by the renters of rooms in a given area; 'Munibnb' would be owned and operated by cities as a public good, enabling them to set controls and caps on short-term rentals; similarly city-managed, 'Allbnb' would add the principle of redirecting the profits

\footnotetext{
${ }^{12}$ http://platform.coop/2015/participants/maria-del-carmen-arroyo.
} 
from the platform back to residents as dividends, recognizing the fact that, when visitors come, their hosts are all the city's residents, not just those from whom they rent a room.

Such municipal ownership models have been pioneered by so-called 'sharing cities' such as Seoul, South Korea, which has restricted certain platforms while promoting the development of local alternatives. Municipal ownership is not strictly cooperative - it violates the cooperative principle of 'autonomy and independence', among others - but this approach recognizes that, as stewards of common infrastructure, governments are essential stakeholders in the platform economies that rely on such infrastructure to operate.

When a business serves the role of organizing and enabling the transactions throughout an entire sector of the economy, it has historically been regarded as either a monopoly or a public utility. Just as the monopolies of connective railroads inspired the U.S. antitrust laws of a century ago, a recognition is growing that new strategies of enforcement, and perhaps new laws, are needed to regulate the emerging online super-platforms (Khan, 2016). Enabling transitions to more democratic ownership designs may be a way to help these platforms better self-regulate, rather than inviting more stifling regulatory regimes.

\section{Designing for the future}

Cooperatives have often formed from a posture of reaction, of meeting unmet and essential needs, rather than anticipating desires or advertising them into existence. The growing movement for platform cooperativism, too, has tended toward imagining co-op versions of existing models, rather than wholesale innovations. While conservatism can be a strength and a source of stability, it will also be a liability in an evolving online economy of capitalrich enterprises competing for winner-take-all market share. Leading offline cooperatives have made a point of investing in innovation, and platform co-ops will need to do so all the more. To this end, Trebor Scholz has formed the Platform Cooperativism Consortium at The New School to orchestrate research and funding specifically for this emerging sector. The Internet of Ownership maintains a library of legal templates and bylaws. And research initiatives like the EU's P2Pvalue project are starting to incorporate platform cooperativism into their work as well. Such efforts face plentiful challenges.

Among the most visible platform co-ops in development, for instance, are 
cooperative taxi companies vying to compete with the likes of Uber. Companies like Green Taxi Cooperative in Denver, Alpha Taxis in Paris and ATX Coop Taxi in Austin are betting that they can provide better service with drivers fully committed to their work through various degrees of equity sharing, combined with their own app-based hailing technology. In the short term this strategy may have promise. However, Uber's longer-term outlook appears to be premised on an eventual transition to self-driving cars - and an economy in which human driver-owners could turn into a cumbersome liability.

The question at hand, really: How do we cooperativize robots? It's a challenge for domains well beyond transportation. The 'internet of things' - the growing industry of automated, networked gadgets, from watches to home temperature controls - poses problems of trust and surveillance that cooperative ownership could be especially well suited for, but only if they move into that new market quickly enough. Platform co-op researchers need to investigate more deliberately what potential innovations and business models investor-owned companies aren't seeing because of the limitations of their own ownership structures.

Matters of intellectual property ownership take on fresh urgency as people invite artificial intelligence more fully into their lives through systems like Amazon's Alexa. Silicon Valley titans Elon Musk and Sam Altman, among others, have formed an organization called OpenAI to develop open-source artificial intelligence technoloegy, but, as with open-source software generally, this does not prevent value from flowing mainly to corporate investors. Peter Barnes (2006), on the other hand, has suggested that those who monetize our information commons could pay fees that would be redistributed equally to the population in the form of a universal dividend. And a team of computer scientists has proposed a preliminary model for artificial intelligence owned by the people whose data-labor trains it (Sriraman et al., 2017). The nature of democratic ownership design for a more automated future is by no means obvious, but investor control need not be a foregone conclusion.

Finally, an honest platform cooperativism should extend its gaze beyond the platform economy itself to its material substrates - in particular, the human conditions surrounding the mineral extraction and assembly of the hardware on which platforms depend. This has been neglected territory for the emerging platform co-op ecosystem, which has remained softwareoriented. But there are some promising points of departure to consider. Fairphone is a Dutch smartphone, available in Britain through The Phone 
Co-op; it is designed with an ethical supply chain in mind, including decent working conditions and conflict-free minerals. The Indonesian co-op KDIM is building its own locally produced smartphone. In China, Huawei, the world's largest telecommunications hardware manufacturer, is significantly employee-owned - though it is neither a formal co-op nor a model for worker rights. Perhaps platform co-ops, by building other co-ops into their supply chains, can help set high standards for sourcing and labor. Further research is needed, however, to develop more democratic ownership designs for the hardware, natural resources and human labor on which any future platform economy will depend.

\section{Ownership transitions}

What would it take to have an economy in which a can-do entrepreneur with an idea for a platform - the kind of person who wants nothing more than to create something new and excellent and receive some fair compensation for succeeding - will conclude that her best way to proceed is by practicing democracy? The answer, of course, is that it would take a lot of things at once. Ownership design is best considered a process of open-ended choices, based on patterns that we test and apply iteratively. Integral to the designs themselves, therefore, are the processes for instantiating them.

There are two basic kinds of co-op development: startups and conversions. Startups that begin as co-ops from their inception have the chance to hardwire cooperative values into their structures and cultures; they typically rely on the widespread recognition of an unmet need. Conversion, meanwhile, involves transitioning an existing enterprise to democratic ownership and governance, combining a proven business model and its existing momentum with a structure better aligned to serve the people who rely on it.

Startups might come in several forms. Some will be bootstrapped - drawing on existing communities of users to finance and populate a platform that meets their needs, perhaps through equity crowdfunding. Along these lines, venture capitalist Brad Burnham of Union Square Ventures envisions a new generation of less risky 'skinny platforms' that deliver lower returns to investors and higher returns to labor. He told Shareable in 2015, 'We can generate a return participating in that, and we think that's what we should be doing' (Geraci, 2015). Other kinds of startups, meanwhile, might spin off from existing cooperatives, online or off, perhaps connected by a federation or other forms of ongoing cooperation. For instance, the German cooperative 
marketplace platform Fairmondo is spreading to the UK through the aid of two existing cooperatives - Fairmondo itself and Worth Cooperating in the UK - with the intention of creating a freestanding multi-stakeholder co-op. Rather than growing as a multinational company, they're replicating and sharing a common pool of open-source software.

Conversions, too, can come in various forms. One is a mature-stage transition. Especially when a product is unproven or lacks a ready community of users, a cooperative structure may not be the appropriate ownership design early on; it makes sense, then, that forward-thinking founders and investors should hold the risk, as well as the opportunity for reward. Once a community of users forms, however, the nature of the business changes, and cooperative ownership models become more appropriate - such as to govern labor policies or the use of personal data. A loyal and active community can provide founders with a fair return for their early innovation and investment; shared ownership, meanwhile, can help keep that community loyal and active and interested in their platform's success. Another kind of conversion - more speculative and challenging, to be sure - could take place once a platform has achieved the sort of ubiquity that makes it, in essence, a monopoly-utility. For instance, as former Harvard Library director Robert Darnton contends (2009 and elsewhere), Google Books has created a unique and essential information commons by scanning and making available documents that may never be scanned again; a company whose chief responsibility is shareholder profit, however, does not seem to be the appropriate steward for an archive of such immesurable value. Similar concerns in the platform co-op networks have spurred a 'BuyTwitter' campaign, which calls on the company to convert to some form of user ownership. A new generation of antitrust policy might finance and aid transfers of platform ownership to the users who depend on them. Cooperative models are both proven and adaptive enough to merit consideration as we design and adopt - so far with too little foresight - the platform utilities of the twenty-first-century economy.

The extent of platform cooperativism at present remains limited to a rallying cry, a few success stories, and a cluster of far-flung, early-stage experiments. Merely saying that it should take hold more widely, as we advocates have attempted to do, is not enough to overcome the formidable barriers of financing, market access, public education and competition that this kind of model faces. Even a brief glance at the existing, offline cooperative economy - the credit unions, the electric utility co-ops, the farmers' marketing and supply firms - makes clear that a more cooperative online economy would not guarantee utopian outcomes. But the achievements of past co-op sectors 
do at least suggest that such models are capable of scaling to reach and shape significant portions of economic life. When they do so, they furnish more resilient, institutionally diverse societies, impacting the behavior of non-cooperative enterprises as well as the lives of their members.

Insofar as platform cooperativism has been a scholarly project, it introduces questions that have been too often neglected in research on internet cultures and economies. How are platforms owned and governed, and how could they be owned and governed differently? How does their ownership shape the platforms' structures of accountability? How do ownership models organize and limit the kinds of technologies available to people?

Thankfully, this has not been merely a scholarly project, but a participatory one. The emerging experiments have not merely followed the path called for or imagined by theory. That dynamism only reinforces the supposition, however, that when we reorient systems of ownership and governance toward democracy, transformative things can occur.

\section{References}

Albæk, S. \& Schultz, C. (1998), 'On the relative advantage of cooperatives', Economics Letters 59 (3).

Alexander, C., Ishikawa, S., \& Silverstein, M. (1977), A Pattern Language: Towns, Buildings, Construction, Oxford: Oxford University Press.

Altenberg, L. (1990). 'An end to capitalism: Leland Stanford's forgotten vision', Sandstone and Tile 14 (1).

Arizmendiarrieta, J. M. (2013), Reflections, Otalora.

Baran, P. (2002), 'The beginnings of packet switching: some underlying concepts', IEEE Communications Magazine 40 (7).

Barbrook, R. \& Cameron, A. (1996 [1995]), 'The Californian ideology', Science as Culture 6, (1).

Barnes, P. (2006), Capitalism 3.0: A Guide to Reclaiming the Commons, San Francisco, CA: Berrett-Koehler Publishers.

Benkler, Y. (2007), The Wealth of Networks: How Social Production Transforms Markets and Freedom, New Haven, CT: Yale University Press. 
Bernasek, A. \& Mongan, D. T. (2015), All You Can Pay: How Companies Use Our Data to Empty Our Wallets, New York: Nation Books.

Bogetoft, P. (2005), 'An information economic rationale for cooperatives', European Review of Agricultural Economics 32 (2).

Bollier, D. (2008), 'Inventing the creative commons', in Viral Spiral: How the Commoners Built a Digital Republic of Their Own, New York: The New Press.

Coleman, G. (2012), Coding Freedom: The Ethics and Aesthetics of Hacking, Princeton, NJ: Princeton University Press.

Conaty, P., Bird, A., \& Ross, P. (2016), Not Alone: Trade Union and Co-operative Solutions for Self-Employed Workers, Co-operatives UK.

Couldry, N. (2016), 'The price of connection: "surveillance capitalism", The Conversation, September 22. Retrieved from: https://theconversation.com/theprice-of-connection-surveillance-capitalism-64124.

Curl, J. (2012), For All the People: Uncovering the Hidden History of Cooperation, Cooperative Movements and Communalism in America, 2nd ed., Oakland, CA: PM Press.

Darnton, R. (2009), 'Google \& the future of books', The New York Review of Books, February 29.

Davidson, A. (2016), 'Managed by Q's 'good jobs" gamble', The New York Times Magazine, February 25.

de Ugarte, D. (2011), 'Tipologías de las cooperativas de trabajo', El Jardín Indiano, September 18. Retrieved from: https://lasindias.blog/tipologias-delas-cooperativas-de-trabajo.

Dryden, A. (2013), 'The ethics of unpaid labor and the OSS community', November 13. Retrieved from: https://ashedryden.com/blog/the-ethics-ofunpaid-labor-and-the-oss-community.

Frank, S. (2015), 'Come with us if you want to live', Harper's Magazine, January.

Gansky, L. (2014), 'Collaborative Economy Companies Need To Start Sharing More Value With the people who make them valuable', Fast Company, December 4. 
Geraci, F. (2015), 'Interviewed: venture capitalist Brad Burnham on skinny platforms', Shareable, June 22. Retrieved from: http://shareable.net/blog/interviewed-venture-capitalist-brad-burnham-onskinny-platforms.

Hansmann, H. (2000), The Ownership of Enterprise, Cambridge, MA: Belknap Press.

Hueth, B. (2014), 'Missing markets and the cooperative firm', Conference on Producer Organizations, Toulouse School of Economics, September 5-6.

Jensen, M. C. (2000), A Theory of the Firm: Governance, Residual Claims and Organizational Forms, Cambridge, MA: Harvard University Press.

Kelly, M. (2012), Owning Our Future: The Emerging Ownership Revolution, Oakland, CA: Berret-Koehler Publishers.

Kelty, C. M. (2008), Two Bits: The Cultural Significance of Free Software and the Internet, Durham, NC: Duke University Press.

Khan, L. (2016), 'How to reboot the FTC', Politico, April 13. Retrieved from: http://politico.com/agenda/story/2016/04/ftc-antitrust-economymonopolies-000090.

Kleiner, D. (2010), The Telekommunist Manifesto, Amsterdam: Institute of Network Cultures.

Kostakis, V. \& Bauwens, M. (2014), Network Society and Future Scenarios for a Collaborative Economy, New York: Palgrave Macmillan.

Linebaugh, P. (2009), The Magna Carta Manifesto: Liberties and Commons for All, Berkeley, CA: University of California Press.

Molk, P. (2014), 'The puzzling lack of cooperatives', Tulane Law Review 88.

Monks, R. A. G. \& Minow, N. (2008), Corporate Governance, 4th ed., London: John Wiley \& Sons.

Parker, G. G., Van Alstyne, M. W., \& Choudary, S. P. (2016), Platform Revolution: How Networked Markets Are Transforming the Economy - And How to Make Them Work for You, New York: W. W. Norton \& Company.

Parmar, B. L., Freeman, R. E., Harrison, J. S., Wicks, A. C., Purnell, L., \& de Colle, S. (2010), 'Stakeholder theory: the state of the art,' The Academy of Management Annals 4 (1). 
Pasquale, F. (2015), The Black Box Society: The Secret Algorithms That Control Money and Information, Cambridge, MA: Harvard University Press.

Pérotin, V. (2016), 'What do we really know about worker co-operatives?' Co-operatives UK.

Said, C. (2014), 'Cooperatives give new meaning to sharing economy', San Francisco Chronicle, May 24.

Schneider, N. (2014), 'Owning is the new sharing', Shareable, December 21. Retrieved from: http://shareable.net/blog/owning-is-the-new-sharing.

Schneider, N. (2015a), '5 ways to take back tech', The Nation, May 27. Retrieved from: https://thenation.com/article/5-ways-take-back-tech.

Schneider, N. (2015b), 'Be the bank you want to see in the world', Vice 22 (4), April.

Schneider, N. (2016). Here's my plan to save Twitter: let's buy it, The Guardian. Retrieved from https://theguardian.com/commentisfree/2016/sep/29/savetwitter-buy-platform-shared-ownership.

Scholz, T. (2014), 'Platform cooperativism vs. the sharing economy'. Retrieved from: https://medium.com/(???)

Scholz, T. (2016a), Platform Cooperativism: Challenging the Corporate Sharing Economy, New York: Rosa Luxembourg Siftung. Retrieved from: http://rosalux-nyc.org/platform-cooperativism-2.

Scholz, T. (2016b), Uberworked and Underpaid: How Workers Are Disrupting the Digital Economy, Cambridge: Polity.

Scholz, T. \& Schneider, N. (eds.) (2016), Ours to Hack and to Own: The Rise of Platform Cooperativism, a New Vision for the Future of Work and a Fairer Internet, New York: OR Books.

Schor, J. (2014), 'Debating the sharing economy', Great Transition Initiative. Retrieved from: http://greattransition.org/publication/debating-the-sharingeconomy.

Slee, T. (2016), What's Yours Is Mine: Against the Sharing Economy, New York: OR Books.

Smith, A. (2016), 'Gig work, online selling and home sharing', Pew Research Center. Retrieved from: http://pewinternet.org/2016/11/17/gig-work-onlineselling-and-home-sharing. 
Spitzberg, D. (2017). \#GoCoop: how the \#BuyTwitter campaign could signal a new co-op economy. The Cooperative Business Journal.

Sriraman, A., Bragg, J., \& Kulkarni, A. (2017), 'Worker-owned cooperative models for training artificial intelligence', CSCW '17 Companion, February 25-March 1.

Sutton, M., Johnson, C., \& Gorenflo, N. (2016). 'A Shareable explainer: what is a platform co-op?' Shareable, August 16. Retrieved from: http://shareable.net/blog/a-shareable-explainer-what-is-a-platform-co-op.

Taylor, K. (2015), 'Learning from the co-operative institutional model', Administrative Sciences 5. 